\title{
Trend and Change Point Detection of Precipitation in Urbanizing Districts of Uttarakhand in India
}

\author{
G. Pranuthi, S.K. Dubey, S.K.Tripathi and S.K. Chandniha \\ Department of Water Resources Development and Management \\ Indian Institute of Technology Roorkee, Roorkee-247667, Uttarakhand, India; \\ sankufwt@gmail.com, sankufwt@iitr.ernet.in
}

\begin{abstract}
Precipitation is the one of the prime indicators of climate change and its aberration causes many extreme events such as floods and droughts. Long-term trends were analyzed as monthly, seasonal and annual rainfall of Haridwar, Dehradun,Udham Singh Nagar, Almora and Nainital using Mann-Kendall and linear regression tests and change point was detected using cumulative deviation and Worsley likelihood statistic. Mann Kendall test revealed that there is significant increase in rainfall only for Haridwar district which has more urbanizing area compared to other districts. Haridwar is the holy place attracting significant floating population from all over the world, especially during festivals and fairs. Anthropogenic activity and industrialization is also the major cause of rainfall trend fluctuation in the Haridwar city. The monthly trend tests show that July rainfall is increasing whereas the December rainfall is decreasing which could be due to the seasonal shift. The start of change in the rainfall trend for the above mentioned districts is observed with distinct difference from 2009 onwards. From this it can be concluded that the stations to the west show significant trends compared to station which is towards east. Monsoon especially in July month a trend of increasing rainfall is observed in the studied Indian cities. The spatial and temporal trends of precipitation are pertinent for the future development and sustainable management of water resources of a given region.
\end{abstract}

Keywords: Change Point, Mann Kendall Trend, Rainfall, Uttarakhand, Worsely Likelihood Test

\section{Introduction}

Basic idea of rainfall pattern is required for a number of hydro meteorological applications like sustainable management of water resources, forecasting of drought and floods, planning for agriculture purpose, urbanization, modeling of hydrological feature, quantification of climate change impact, estimation of water balance and irrigation management for sustainable crop production ${ }^{11}$. Rainfall is the one of the most important factors of hydrometeorology that is severely affected by climate change impact $^{2}$. Prediction of rainfall characteristics is very difficult due to its variability both spatially and temporally ${ }^{28}$. Variability of rainfall in hilly tract of Uttarakhand region is more due to its natural topography as well as anthropogenic effect ${ }^{29}$. Yet there are number of researchers who tried to investigate the variability of rainfall, its pattern, intensity etc. on a macro scale ${ }^{1,3,4}$ but the pattern of rainfall trend on small scale is still unexplored.

The changes in rainfall pattern have been reported by several researchers and predicted to change further ${ }^{2}$. The Intergovernmental Panel on Climate Change $(\text { IPCC })^{5}$ reported the seasonal, annual and spatial variability in rainfall trends during the past few decades all across Asia. Numbers of studies have been carried out in various spatial and temporal scales. Many authors analyzed the rainfall patterns for several parts of India in a minor spatial scale $e^{8,24,26,33}$ and reported that there is no clear trend of increase or decrease in average rainfall over the country. Study conducted on all India scale (macro scale) $)^{10,15,24}$ indicated that intra-region variability for extreme monsoon seasonal rainfall is large and mostly exhibited a negative trend leading to increased frequency and magnitude of monsoon rainfall while the annual

*Author for correspondence 
rainfall shows no significant trend except in the peninsular Indian region. Kumar and Jain ${ }^{18}$ carried out a detailed analysis to determine the trends in rainfall amount and the number of rainy days over major Indian River basins using daily gridded rainfall and reported that the six river basins had increasing trend in annual rainfall and 15 river basins had the decreasing trend, whereas the Ganga basin had no trend. Few studies have reported that the annual precipitation would increase in future in India for some particular months $s^{9,14,17,18,19,22}$. Patra et al..$^{25}$ reported increasing trend during the months of January, August and September months in India.

There are number of parametric and non-parametric statistical test available to examine the trend of hydro meteorological parameters ${ }^{6}$. Parametric tests are more powerful as compared to non-parametric test but they require independent and normally distributed data series while non-parametric test requires only data to be independent data and they also have the ability to remove outliers. Most important and frequently test used for the analysis of rainfall trend is Mann Kendal (MK) Trend Test ${ }^{16,21}$ and Spearman's Rho (SR) which are frequently used in number of hydro meteorological studies ${ }^{17,31}$. Comparative study of MK and SR shows that both the methods have similar capacity of detecting monotonic trends ${ }^{7}$.

The objective of this study is to determine the trend of rainfall on saptio-temporalbasis in the selected district of Uttarakhand state which is most prone to high rainfall variability using Mann Kendall (MK)Test and Spearman's Rho (SR) Test trend test. Magnitude of slope was observed by using Thiel-Sen method ${ }^{30,34}$ method and change in trend is detected by using Worsely likelihood technique and CUSUM method. Change-point analysis was done to detect abrupt climate variations.

\section{Study Area}

Uttarakhand is situated in the foot hills of the great Himalaya lies between $28^{\circ} 43^{\prime} 31^{\circ} 27^{\prime} \mathrm{N}$ and $77^{\circ} 33^{\prime}-81^{\circ}$ $02^{\prime} \mathrm{E}$ and famous for its recreational beauty of natural resources (Table 1; Figure 1). Uttarakhand has about 13 percent of its geographic area under cultivation, out of which about eighty percent of the land does not have assured irrigation facilities thus making agriculture crops totally dependent on vagaries of nature. The state situated centrally in the long sweep of the Himalaya, forms a transitional zone between the per-humid eastern and the dry to sub-humid western Himalaya. The average annual rainfall of the state, as recorded is 1,547 mm. Altitude varies from 200 meter to more than 8400 meters from sea level. The temperature in hilly region goes occasionally below freezing point particularly during winter. The state comprises of two sub major division Garhwal and Kumaonwith a total of 13 districts. More than 70 percent of population is directly or indirectly engaged in agriculture. This sector is poorly developed because of inaccessibility due to topographic condition and vulnerability of climate. As per the availability of long term data only five district of the state is selected in the study i.e., Haridwar, Dehradun, Almora, Nainital, and Udham Singh Nagar. Observed data of precipitation were acquired from Indian Metrological Department (IMD), Pune.

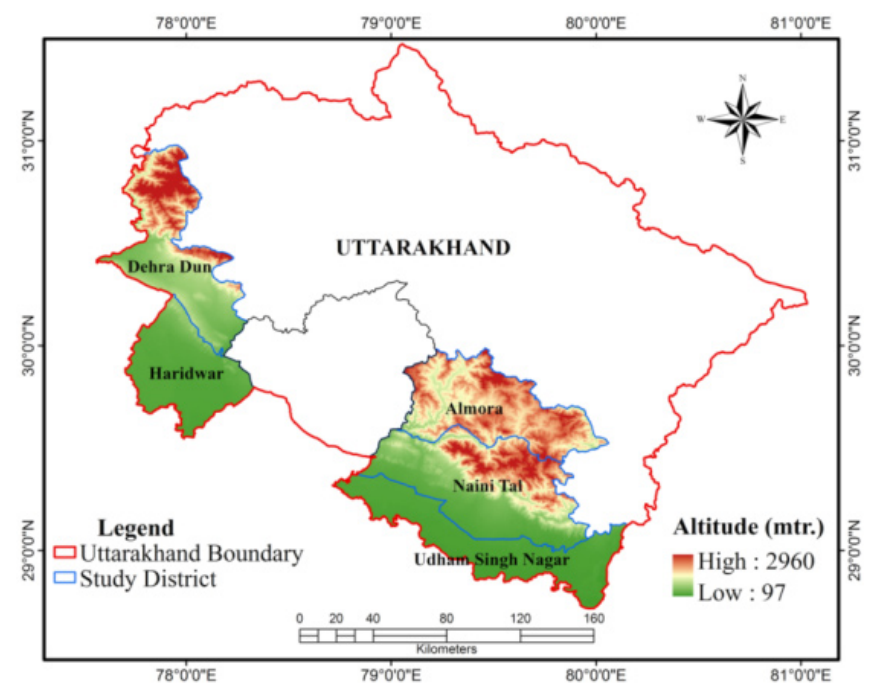

Figure 1. Demographic elevation map of study location in Uttarakhand.

Table 1. Details of study areaof Uttarakhand in India

\begin{tabular}{lccccc}
\hline District & Lat & Long & Alt & $\begin{array}{l}\text { Data } \\
\text { Period }\end{array}$ & $\begin{array}{l}\text { Rainfall } \\
(\mathrm{mm})\end{array}$ \\
\hline Almora & $29^{\circ} 37^{\prime} \mathrm{N}$ & $79^{\circ} 40^{\prime} \mathrm{E}$ & 1651 & $1987-2011$ & 1183 \\
Haridwar & $29^{\circ} 58^{\prime} \mathrm{N}$ & $78^{\circ} 13^{\prime} \mathrm{E}$ & 268 & $1979-2011$ & 1015 \\
Dehradun & $30^{\circ} 19^{\prime} \mathrm{N}$ & $78^{\circ} 04^{\prime} \mathrm{E}$ & 640 & $1979-2010$ & 2171 \\
US Nagar & $29^{\circ} 43^{\prime} \mathrm{N}$ & $79^{\circ} 70^{\prime} \mathrm{E}$ & 550 & $1970-2010$ & 1218 \\
Nainital & $29^{\circ} 23^{\prime} \mathrm{N}$ & $79^{\circ} 30^{\prime} \mathrm{E}$ & 2084 & $1980-2010$ & 1493 \\
\hline
\end{tabular}




\section{Statistical Methods}

\subsection{Non-parametric Test}

Non-parametric statistics are usually much less affected by the presence of outliers and other forms of nonnormality ${ }^{20}$. The most frequently used non-parametric test for identifying trends in hydrologic variables is the Mann-Kendall (MK) test. The statistical significance trend detected using a non-parametric model such as MannKendall (MK) test can be complemented with Sen's slope estimation to determine the magnitude of the trend.

\subsection{Mann-Kendall Trend Test}

Mann Kendal statistics $(S)$ is defined as $^{27}$ follows:

$$
S=\sum_{i=1}^{N-1} \sum_{j=i+1}^{N} \operatorname{sgn}\left(x_{j}-x_{i}\right)
$$

where, $N$ is the number of data points. Assuming $(x j-x i)=\theta$, the value of $\operatorname{sgn}(\theta)$ is computed as follows:

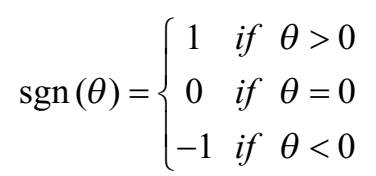

It has been documented that when $n \geq 8$, the statistic $S$ is normally distributed with the mean.

$$
\mathrm{E}(\mathrm{S})=0
$$

The variance is written as-

$$
\delta(S)=\frac{N(N-1)\left(2 N+5-\sum_{i=1}^{m}\left(t_{i}-1\right)\left(2 t_{i}+5\right)(\mathrm{iv})\right.}{18}
$$

where, $\mathrm{N}$ is the number of ties group and $t_{\mathrm{i}}$ the number of data points in the $t_{\mathrm{ih}}$ tied group. Then $Z$-statistics computed ${ }^{12}$ as:

$$
Z=\left\{\begin{array}{ccc}
\frac{S-1}{\sqrt{\operatorname{Var}(S)}} & \text { if } & S>0 \\
0 & \text { if } & S=0 \\
\frac{S+1}{\sqrt{\operatorname{Var}(S)}} & \text { if } & S<0
\end{array}\right.
$$

Here $\mathrm{Z}$ follows standard normal distribution. A positive value of $\mathrm{Z}$ indicates upward trend and negative value indicate downward trend. A significance value $\alpha$ is utilized for testing either an upward or downward trend in a two sided test. If the $Z$ value is greater than $Z_{\alpha / 2}$, then null hypothesis $\left(H_{0}\right)$ is rejected at a level of significance.

\subsection{Theil-Sen's Estimator}

The slope of $n$ pairs of data points was estimated using the Theil-Sen's estimator ${ }^{30,34}$ which is given by the following relation:

$$
\beta=\operatorname{Median} \frac{x_{j}-x i}{j-i} \text { forall } i \leq j
$$

In which $1<j<i<n$ and $\beta$ is the robust estimate of the trend magnitude. A positive value of $\beta$ indicates an 'upward trend' while a negative value of $\beta$ indicates a 'downward trend'0.

\subsection{Spearman's Rho Test}

Spearman's Rho is a rank-based test for correlation between two variables that can be used to test for correlation between time and the data series ${ }^{32}$. Spearman's correlation is a rank-based version of the usual parametric measure of correlation. In trend analysis; one variable is taken as the time itself (years) and the other as the corresponding time series data.

Like the Mann-Kendall Test, the $\mathrm{n}$ time series values are replaced by their ranks. The test statistic $\rho$ is the correlation coefficient, which is obtained in the same way as the usual sample correlation coefficient, but using ranks:

Test statistics is defined by Siegel and Castellan ${ }^{32}$ as:

$$
\rho_{S}=\frac{S_{X Y}}{\sqrt{\left(S_{X} S_{y}\right)}}
$$

where,

$$
\begin{aligned}
& S_{X}=\sum_{i=1}^{n}\left(X_{i}-\bar{X}\right)^{2} \\
& S_{Y}=\sum_{i=1}^{n}\left(Y_{i}-\bar{Y}\right)^{2} \\
& S_{X Y}=\sum_{i=1}^{n}\left(X_{i}-\bar{X}\right)^{2}\left(Y_{i}-\bar{Y}\right)
\end{aligned}
$$

And $\mathrm{X}_{\mathrm{i}}$ (time), $\mathrm{Y}_{\mathrm{i}}$ (variable of interest), $\mathrm{x}$ and $\mathrm{y}$ refer to the ranks $\left(\mathrm{x}, \mathrm{y}, \mathrm{S}_{\mathrm{x}}\right.$ and $\mathrm{S}_{\mathrm{y}}$ have the same value in a trend analysis).

For large samples, the quantity $\rho_{S}=\sqrt{n-1}$ is approximately normally distributed with mean of 0 and variance of 1 (critical test statistic values for various significance levels can be obtained from normal probability tables). 


\subsection{Worsley Likelihood Ratio Test}

The ratio test developed by Worsley ${ }^{35}$ gives the jump in between the time series and this indicates the initiation of change. This method tests whether the means in two parts of a record are different (for an unknown time of change). The test assumes that the data are normally distributed.

$$
\begin{gathered}
Z_{W}=[K(n-K)]^{0.5} \times S S \\
Z_{W}=\frac{Z_{w}}{d_{x}}
\end{gathered}
$$

Test statistics $\mathrm{W}$ is defined by Worsley ${ }^{35}$ as:

$$
W=\frac{(n-2)^{0.5} V}{\left(1-V^{2}\right)^{0.5}}
$$

where,

$$
\begin{aligned}
& V=\operatorname{Max}\left|Z_{w}\right| \\
& \mathrm{n}= \text { No. of observations. } \\
& \mathrm{K}= \text { weight assigned to SS } \\
& \mathrm{SS}= \text { sum of squares } \\
& \mathrm{W}=\text { Worsley LikelihoodRatio Test } \\
& \mathrm{Z}_{\mathrm{w}}=\text { WorselyTeststatistic } \\
& \mathrm{Z}_{\mathrm{w}}=\text { Test quotient } \\
& \mathrm{V}=\text { any convenient statistic }
\end{aligned}
$$

The critical test statistic values for various significance levels for all selected observations are 2.869, 3.159 and 3.79 at 90,95 and $99 \%$ probability levels.

\subsection{CUSUM Test}

This method tests whether the means in two parts of a record are different (for an unknown time of change). It is a nonparametric test (distribution free). Given a time series data $\left(\mathrm{X}_{1}, \mathrm{X}_{2}, \mathrm{X}_{3} \ldots \mathrm{X}_{\mathrm{n}}\right)$, the test statistic is defined as:
CUSUM change statistics $\left(\mathrm{V}_{\mathrm{k}}\right)$ is defined by Inclan and Tiao ${ }^{13}$ follows:

$$
V_{k}=\sum_{i=1}^{k} \operatorname{sgn}\left(X_{i}-X_{\text {medium }}\right)
$$

where, $\mathrm{k}=1,2,3 \ldots \ldots \ldots$.

$$
\operatorname{sgn}(X)=\left\{\begin{array}{c}
1 \text { if } \theta>0 \\
0 \quad \text { if } \theta=0 \\
-1 \text { if } \theta<0
\end{array}\right.
$$

$\mathrm{X}_{\text {median }}$ is the median of $\mathrm{X}$ dataset.

This is a rank-based test in which successive observations are compared with the median of the series ${ }^{7}$. The test statistic is the maximum CUmulative SUm (CUSUM) of the signs of the difference from the median (i.e. the CUSUM of a series of values of +1 or -1 ) starting from the beginning of the series.

\section{Results and Discussion}

\subsection{Rainfall Characteristics}

The rainfall characteristics of the study area are presented in Table 2 and Table 3.Mean annual rainfall is $1481.1 \mathrm{~mm}$

\begin{tabular}{|c|c|c|c|c|c|c|c|c|c|}
\hline \multicolumn{10}{|c|}{ Rainfall Analysis - Haridwar 1979-2011 } \\
\hline \multirow[b]{3}{*}{ Months } & \multicolumn{4}{|c|}{ Trend statistics } & \multicolumn{4}{|c|}{ Change statistics } & \multirow[b]{3}{*}{ Mean RF } \\
\hline & \multicolumn{2}{|c|}{ MK Test } & \multicolumn{2}{|c|}{ Spearman's Rho } & \multicolumn{2}{|c|}{ CUSUM } & \multicolumn{2}{|c|}{ Worsley likelihood } & \\
\hline & $\mathrm{Z}$ & $S$ & $\mathrm{Z}$ & Rho & Max Dev & YOC & $\mathrm{W}$ & YOC & \\
\hline Jan & -1.26 & -0.53 & -1.3 & -0.23 & 5 & 1983 & 2.33 & 2005 & 27.64 \\
\hline Feb & 0.4 & 0.19 & 1.04 & 0.18 & 7 & 1987 & 2.19 & 1987 & 37.15 \\
\hline Mar & -0.31 & 0 & -0.42 & -0.08 & 3 & 2011 & 1.78 & 1982 & 24.57 \\
\hline Apr & -0.03 & 0 & 0.34 & -0.06 & 6 & 2006 & 2.09 & 1983 & 17.17 \\
\hline
\end{tabular}
with a standard deviation of $197.7 \mathrm{~mm}$. Monsoon rainfall contributes $78.8 \%$ and winter rainfall contributes $2.5 \%$ of the annual rainfall. During the monsoon season the coefficient of variation is very low (14.2\%) compared to other seasons which shows a dependable monsoon rainfall. However, the spatial and temporal distribution of daily rainfall during monsoon season is very much uneven with either flooding or drought condition during the season. Figure 2 provides the Spatial Trend of Rainfall in the study area.

Table 2. Monthly rainfall trends and change points for Haridwar, Dehradun, Udham Singh Nagar, Almora and Nainital districts. 


\begin{tabular}{|c|c|c|c|c|c|c|c|c|c|}
\hline May & 1.32 & 0.71 & 1.27 & 0.23 & 6 & 1998 & 2.36 & 2010 & 36.01 \\
\hline Jun & -0.27 & -0.2 & -0.31 & -0.06 & 5 & 1999 & 2 & 1999 & 103.3 \\
\hline Jul & $2.16^{\star *}$ & 3.83 & $2.29^{\star *}$ & 0.41 & 7 & 2005 & $3.5^{\star \star}$ & 2009 & 292.11 \\
\hline Aug & 1.07 & 1.69 & 1.12 & 0.2 & 4 & 2008 & 2.07 & 1979 & 279.77 \\
\hline Sep & 1.08 & 1.99 & 1.04 & 0.18 & 7 & 1987 & 2.19 & 1987 & 155.9 \\
\hline Oct & 0.79 & 0 & 1.78 & 0.31 & 6 & 1994 & 1.3 & 1995 & 21.99 \\
\hline Nov & 0.05 & 0 & 1.55 & 0.27 & 6 & 2002 & 2.65 & 1981 & 5.44 \\
\hline Dec & -1.4 & -0.1 & -1.19 & -0.21 & $10^{*}$ & 1990 & 2.24 & 1990 & 14.11 \\
\hline Annual & $1.90^{*}$ & 9.50 & $2.01^{\star \star}$ & 0.55 & 6 & 1993 & $2.89^{\star}$ & 2009 & 1015.2 \\
\hline \multicolumn{10}{|c|}{ Rainfall Analysis - Dehradun 1979-2010 } \\
\hline Jan & -1.41 & -0.95 & -1.48 & -0.27 & 5 & 2005 & 2.66 & 2005 & 42.98 \\
\hline Feb & 0.05 & 0.026 & -0.05 & -0.01 & 3 & 1993 & 1.44 & 1979 & 57.4 \\
\hline Mar & -1.12 & -0.625 & -1.22 & -0.22 & 3 & 2007 & $3.12^{\star}$ & 1983 & 62.03 \\
\hline Apr & 0 & -0.002 & -0.19 & -0.03 & 4 & 1988 & 1.13 & 2002 & 32.61 \\
\hline May & 0.21 & 0.218 & 0.25 & 0.04 & 5 & 1987 & 1.51 & 1996 & 66.51 \\
\hline Jun & 0.08 & 0.29 & -0.07 & -0.02 & 5 & 2001 & 1.06 & 2008 & 227.96 \\
\hline Jul & $1.67^{\star}$ & 5.834 & $1.64^{\star}$ & 0.29 & 6 & 1996 & 2.07 & 2009 & 633.16 \\
\hline Aug & 0.44 & 1.322 & 0.5 & 0.09 & 3 & 1991 & 1.81 & 2009 & 685.8 \\
\hline Sep & $1.83^{\star}$ & 5.049 & $1.85^{\star}$ & 0.33 & 6 & 1994 & $5.44^{\star * *}$ & 2009 & 291.53 \\
\hline Oct & 0.98 & 0.307 & 1.27 & 0.23 & 3 & 1995 & 1.24 & 1984 & 41.68 \\
\hline Nov & -0.82 & 0 & -0.09 & -0.02 & 3 & 2007 & 3.1 & 1981 & 8.54 \\
\hline Dec & $-2.02^{\star \star}$ & -0.338 & -1.74 & -0.31 & $7.00^{*}$ & 1991 & $3.17^{\star \star}$ & 1991 & 21.34 \\
\hline Annual & 1.22 & 12.18 & 0.23 & 1.29 & $7.00^{*}$ & 1995 & 2.54 & 2009 & 2171.5 \\
\hline
\end{tabular}

Rainfall Analysis - Udham Singh Nagar 1980-2010

\begin{tabular}{|c|c|c|c|c|c|c|c|c|c|}
\hline & $\mathrm{Z}$ & $S$ & $\mathrm{Z}$ & Rho & Max Dev & YOC & W & YOC & \\
\hline Jan & -0.97 & -0.213 & -0.89 & -0.61 & 4 & 2005 & 2.43 & 2005 & 28.02 \\
\hline Feb & 0.6 & 0.133 & 0.67 & 0.12 & 4 & 1993 & 1.32 & 1983 & 36.32 \\
\hline Mar & -1.38 & -0.333 & -1.45 & -0.27 & 4 & 1993 & 2.12 & 1982 & 21.91 \\
\hline Apr & -0.44 & -0.1 & -0.43 & -0.08 & 4 & 2001 & 1.67 & 1986 & 20.41 \\
\hline May & 1 & 0.653 & 1.03 & 0.19 & 6 & 1997 & 1.94 & 1997 & 42.85 \\
\hline Jun & 1 & 2.28 & 0.96 & 0.18 & 6 & 1999 & $3.01^{\star}$ & 1999 & 179.13 \\
\hline Jul & -0.22 & -0.747 & -0.31 & -0.06 & 5 & 2006 & 2.25 & 1988 & 422.95 \\
\hline Aug & 1.58 & 5.358 & $1.82^{\star}$ & 0.33 & $8^{\star *}$ & 2001 & 2.42 & 2002 & 422.67 \\
\hline Sep & 1.22 & 3.75 & 1.37 & 0.25 & 3 & 1996 & 2.44 & 2009 & 263.05 \\
\hline Oct & -0.04 & 0 & 0.63 & 0.12 & 5 & 2006 & 1.11 & 1999 & 35.69 \\
\hline Nov & 0.27 & 0 & $1.75^{\star}$ & 0.32 & 5 & 1988 & 0.97 & 1988 & 4.41 \\
\hline Dec & -3.01 & -0.706 & $-2.47^{\star \star}$ & -0.45 & $10^{*}$ & 1991 & $2.88^{*}$ & 1991 & 15.96 \\
\hline Annual & 1.19 & 11.42 & 0.23 & 1.29 & 3 & 2006 & 2.43 & 2002 & 1493.4 \\
\hline \multicolumn{10}{|c|}{ Rainfall Analysis - Almora 1987 - 2011} \\
\hline Jan & -1.65 & -1.427 & $1.65^{\star}$ & -0.34 & 5 & 2005 & $2.97^{\star}$ & 2005 & 41.2 \\
\hline Feb & -0.63 & -0.705 & 0.7 & -0.14 & 2 & 1990 & 1.09 & 1990 & 63 \\
\hline Mar & -1.24 & -1.231 & -1.32 & -0.27 & 3 & 2007 & 2.19 & 1993 & 44.8 \\
\hline Apr & -0.35 & -0.29 & -0.32 & -0.07 & 2 & 2008 & 1.96 & 1988 & 38.3 \\
\hline
\end{tabular}


Table 2. (Continued)

Rainfall Analysis - Haridwar 1979-2011

\begin{tabular}{|c|c|c|c|c|c|c|c|c|c|}
\hline \multirow[b]{3}{*}{ Months } & \multicolumn{4}{|c|}{ Trend statistics } & \multicolumn{4}{|c|}{ Change statistics } & \multirow[b]{3}{*}{ Mean RF } \\
\hline & \multicolumn{2}{|c|}{ MK Test } & \multicolumn{2}{|c|}{ Spearman's Rho } & \multicolumn{2}{|c|}{ CUSUM } & \multicolumn{2}{|c|}{ Worsley likelihood } & \\
\hline & $\mathrm{Z}$ & $S$ & $\mathrm{Z}$ & Rho & Max Dev & YOC & $\mathrm{W}$ & YOC & \\
\hline May & 0.58 & 0.657 & 0.68 & 0.14 & 3 & 2007 & 2.18 & 2005 & 73.4 \\
\hline Jun & 0.77 & 1.801 & 0.77 & 0.16 & 2 & 2010 & 1.92 & 2010 & 156.6 \\
\hline Jul & 1.14 & 2.933 & 1.15 & 0.23 & 4 & 2006 & 2.53 & 2009 & 267.8 \\
\hline Aug & 0 & -0.02 & 0 & 0 & 3 & 2009 & $3.06^{*}$ & 2010 & 286.2 \\
\hline Sep & 1.1 & 2.638 & 1.12 & 0.23 & 3 & 1997 & 1.86 & 2009 & 165.1 \\
\hline Oct & 1.59 & 0.576 & 1.82 & 0.37 & 5 & 2003 & 2.12 & 1995 & 21.8 \\
\hline Nov & 0.31 & 0 & 0.81 & 0.17 & 5 & 2005 & 1.04 & 1999 & 6.9 \\
\hline Dec & -1.15 & -0.239 & -1.21 & -0.25 & 5 & 1991 & $3.54^{\star *}$ & 1991 & 18.2 \\
\hline Annual & 1.28 & 6.421 & 1.15 & 0.23 & 4 & 2006 & 2.53 & 2009 & 1183.2 \\
\hline \multicolumn{10}{|c|}{ Rainfall Analysis - Nainital 1970 - 2010} \\
\hline Jan & -0.83 & -0.266 & -0.69 & -0.11 & 4 & 2005 & 2.28 & 2005 & 40.9 \\
\hline Feb & 0.98 & 0.553 & 1.1 & 0.17 & $8^{* *}$ & 1989 & 1.89 & 1999 & 55.9 \\
\hline Mar & -0.18 & -0.09 & -0.22 & -0.03 & 4 & 1983 & 1.59 & 2007 & 46.3 \\
\hline Apr & $1.83^{\star *}$ & $0.667^{*}$ & $1.90^{\star *}$ & 0.30 & 4 & 1993 & $2.94^{\star}$ & 1981 & 37.8 \\
\hline May & 0.69 & 0.423 & 0.72 & 0.11 & 5 & 1996 & 2.17 & 1971 & 61.6 \\
\hline Jun & 0.04 & 0.046 & 0.1 & 0.02 & 4 & 1995 & 1.86 & 2008 & 136.2 \\
\hline Jul & -0.33 & -0.35 & -0.16 & -0.03 & 6 & 1979 & 1.68 & 2009 & 265.2 \\
\hline Aug & 0.89 & 1.273 & 0.82 & 0.13 & 5 & 2006 & 1.93 & 2006 & 269.9 \\
\hline Sep & 1.57 & 3.403 & 1.56 & 0.25 & $10^{\star}$ & 1997 & 2.56 & 2004 & 219.9 \\
\hline Oct & -1.05 & -0.27 & -0.71 & -0.11 & 6 & 1975 & 1.71 & 1985 & 56.4 \\
\hline Nov & 1.12 & 0 & $2.40^{\star *}$ & 0.38 & 5 & 1988 & 1.35 & 1978 & 9.5 \\
\hline Dec & -0.23 & 0 & 0.29 & 0.05 & 6 & 1991 & 1.39 & 1997 & 18 \\
\hline Annual & 1.36 & 6.179 & 1.41 & 0.22 & 6 & 2001 & 1.35 & 2006 & 1217.5 \\
\hline
\end{tabular}

Table 3. Critical values of MKTT, Spearman's Rho, CUSUM and Worsley likelihood tests at different levels of significance.

\begin{tabular}{ccccc}
\hline & \multicolumn{4}{c}{ Tests of Trend and Change Point Detection } \\
\cline { 2 - 5 } Level of Significance & MKTT $(\mathrm{Z})$ & Spearmans rho $(\mathrm{Z})$ & CUSUM (Max Dev) & WorselyLiklihood (W) \\
\hline$* * *=0.01$ & 2.576 & 2.576 & 7.114 & 3.790 \\
$* *=0.05$ & 1.960 & 1.960 & 7.930 & 3.160 \\
$*=0.10$ & 1.645 & 1.645 & 9.504 & 2.870 \\
\hline
\end{tabular}

\subsection{Haridwar}

MK Trend of monthly rainfall and year of change between the periods 1979 to 2012 was examined by using the equation (i-v) and equation (vi) respectively for Haridwar district revealed that negative trend was observed for January, March, April, June and December month with both the tests but the value was statistically not significant. While February, May, July, August, September, October and November was having positive trend examined with both parametric tests. But the trend was only significant for July month. Sen's slope indicated that the rate of change in July rainfall was $3.83 \mathrm{~mm} /$ year. Significant 
change point for this trend was detected as year 2009 by Worsley likelihood technique (equation -viii) while year 2005 was detected by CUSUM technique (equation- ix and $\mathrm{x}$ ) but the value was not significant. CUSUM has detected a significant change point for December but the corresponding trend result of this month was insignificant. Annual rainfall for this station has significant increasing trend as stated by both methods and the year of change was observed as 2009.

\subsection{Dehradun}

Trend statistics of the Dehradun station from the period 1979-2010 was detected and revealed that negative trend was observed for January, March, November and December month but the change was significant for December month only. Positive trend of rainfall was observed for the month of February, April, May, June, July, August, September and October but the value was statistically significant for July and September month. The rate of change for this two month was 1.67 and $1.83 \mathrm{~mm} /$ year. Significant change point for December month rainfall was detected as year 1991 by CUSUM and Worsley likelihood method. Although four significant changes point (March, July, September and December) in a year has been carried out by Worsley likelihood method but corresponding trend was significant for September and December only. Sen's slope estimate shows that the significant rate of change for December month was very minimal i.e. 0.3 $\mathrm{mm} /$ year while for September and December it was 5.8 and $5.0 \mathrm{~mm}$ respectively. Annual rainfall for this station have positive trend but the statistics is not significant. Abrupt change in annual rainfall was detected from 1995 by CUSUM method.

\subsection{Udham Singh Nagar}

Rainfall data analysis from the period 1980-2010 revealed that total six month i.e. January, March, April, July, October and December) have negative trend of rainfall; whereas positive trend was observed for February, June, August, September and November month. The trend was statistically significant for December month by both the methods and change point for that particular month was detected as 1991. Significant positive trend for the month August was detected by Spearman's Rho method but the trend was not significant with MK Test; whereas change point for this month was year 2001. Not significant trend was observed for annual rainfall.

\subsection{Almora}

Rainfall data analysis pertaining to Almora station from the period 1987-2011 revealed that trend statistics for January, February, March, April and December having negative trend by both methods while May, June, July, September, October and November having positive trend.

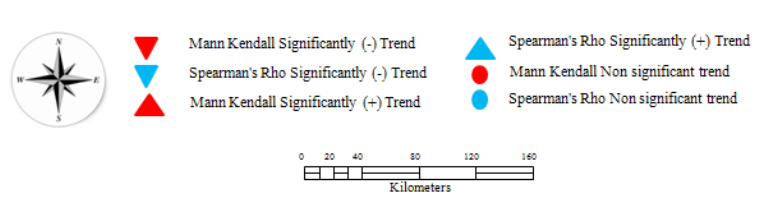

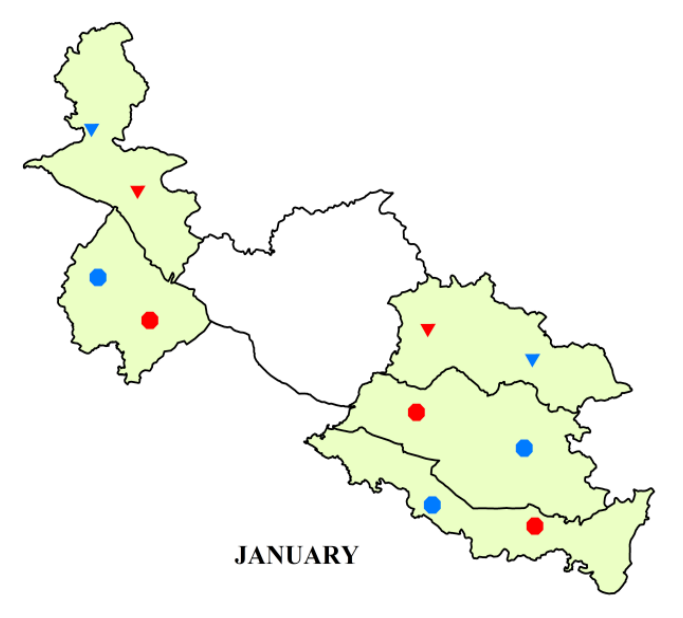

Vol 7 (10) | October 2014 | www.indjst.org

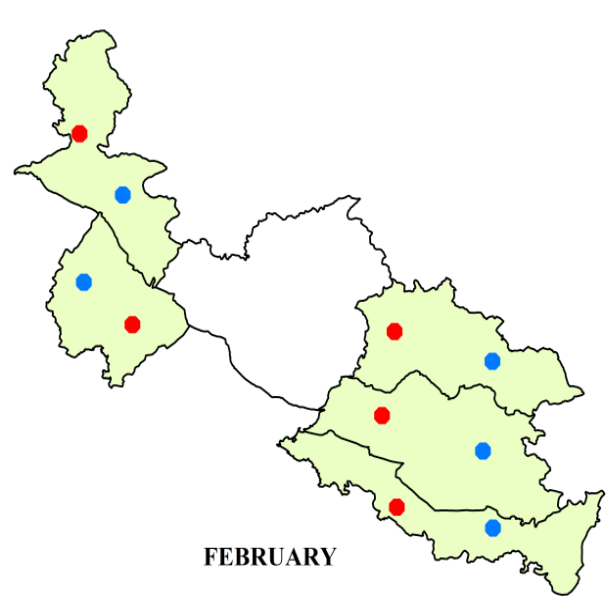

Indian Journal of Science and Technology

| 1579 

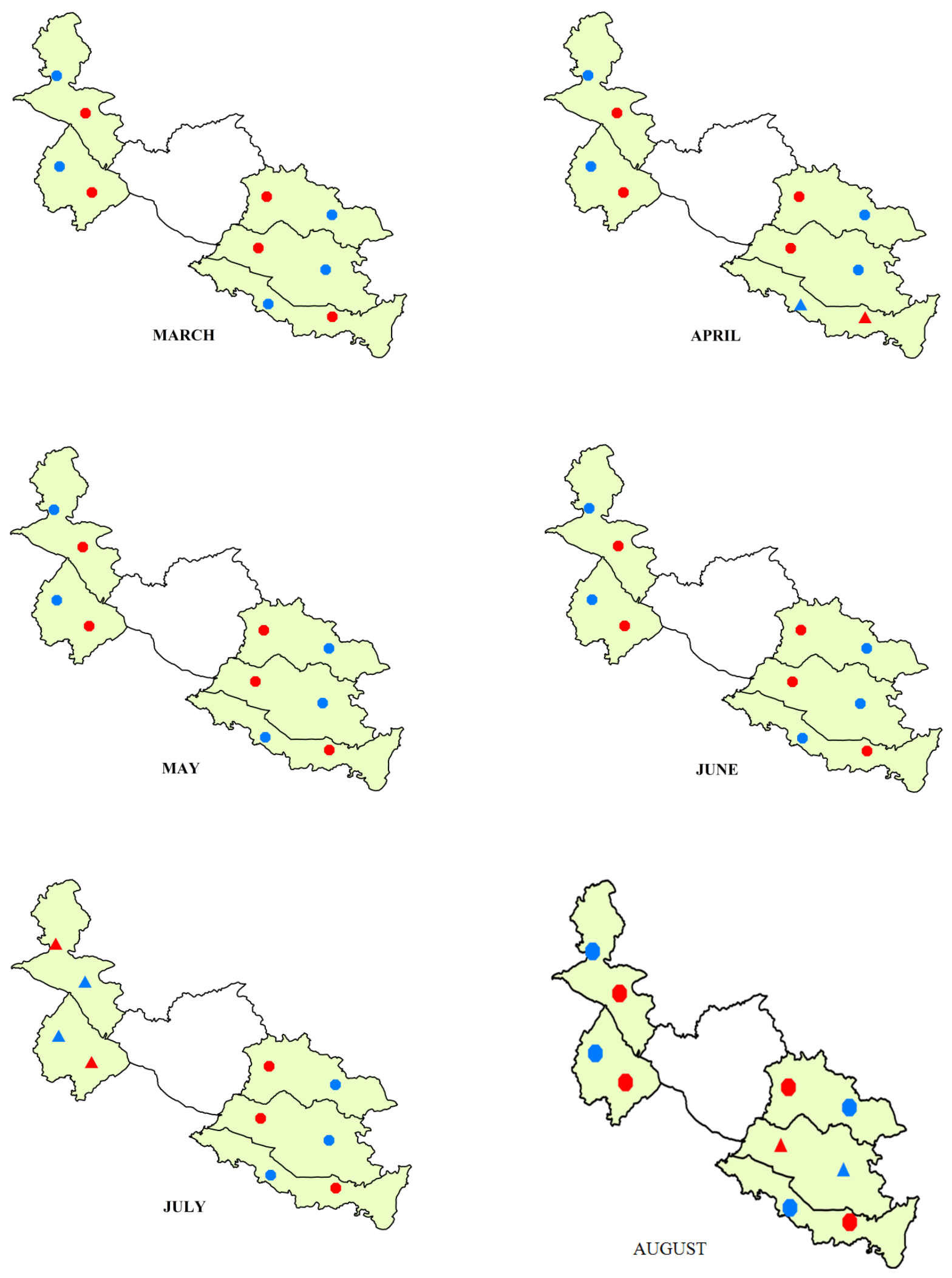

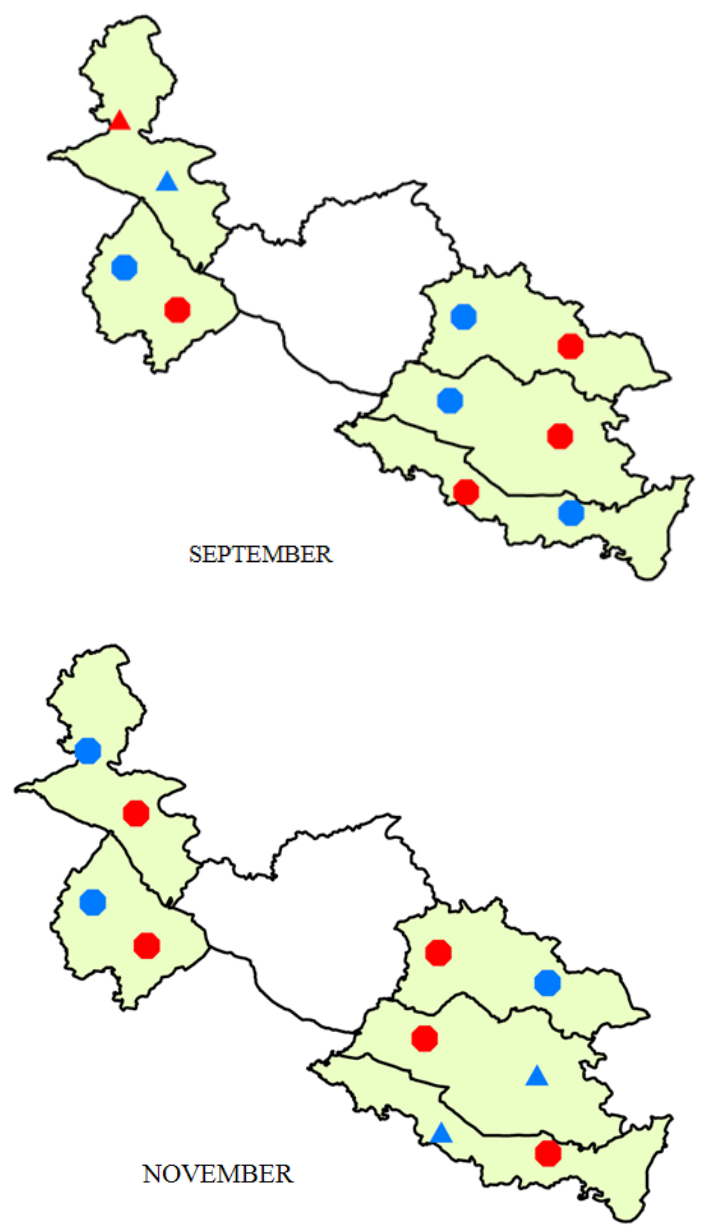

Figure 2. Spatial Trend of Rainfall in the study area.

\section{Conclusion}

Long term rainfall over study area, was analyzed for temporal trend at monthly and annual basis. The investigation showed a long term insignificant declining trend of annual as well as monsoon rainfall, where as an increasing trend in postmonsoon season. During monsoon season the monthly rainfall in the June, July and September months were found to be in decreasing trend, but there was increasing trend in the month of August. The trend is even more evident in last 10 years. Though the analyzed trends might be statistically insignificant in nature, it has high practically significant effects in managing resources and agricultural activities over the region. In this study mainly focused on long variation of trend with different level of significance and change point detection of the time series. Whereas, the shorter period of recent data set showing higher significance may have better practical utility assuming
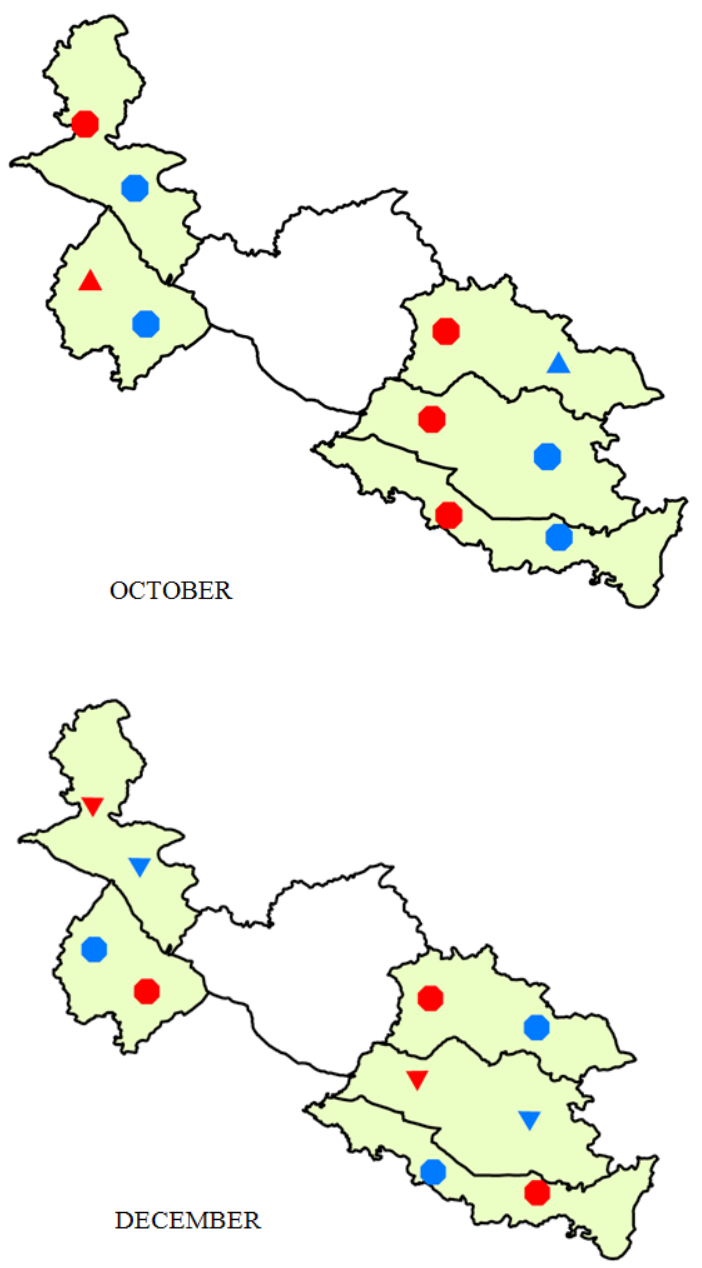

a better explanation of accelerated change in climate pattern and thus have greater impact on natural resources. Trend and change point detection techniques is very fruitful for future prospective i.e., irrigation as well as water resources planning and associated with real world problem.

\section{References}

1. Agarwal A, Bhatnaga N, Nema R, Agrawal NK. Rainfall dependence of springs in the Midwestern Himalayan hills of Uttarakhand. Mt Res Dev. 2012; 32:446-55.

2. Alexander L, Zhang X, Peterson T, Caesar J, Gleason B, Tank AK, Haylock M, Collins D, Trewin B, Rahimzadeh F. Global observed changes in daily climate extremes of temperature and precipitation.Journal of Geophysical Research: Atmospheres. 2006; 111(D5).

3. Arora M, Singh P, Goel N, Singh R. Spatial distribution and seasonal variability of rainfall in a mountainous basin in the Himalayan region. Water Resour Manag. 2006; 20:489-508. 
4. Basistha A, Arya D, Goel N. Spatial distribution of rainfall in Indian himalayas-a case study of Uttarakhand region. Water Resour Manag. 2008; 22:1325-46.

5. Bernstein L, Bosch P, Canziani O, Chen Z, Christ R, Davidson O, Hare W, Huq S, Karoly D, Kattsov V. IPCC, 2007: climate change 2007: synthesis report. Contribution of working groups I. II and III to the Fourth Assessment Report of the Intergovernmental Panel on Climate Change. Intergovernmental Panel on Climate Change, Geneva; 2007. Available from: www.ipcc. ch/ipccreports/ar4-syr. htm

6. Chen SX, Gao J. An adaptive empirical likelihood test for parametric time series regression models. J Econometrics. 2007; 141, 950-72.

7. Yue S, Pilon P, Cavadias G. Power of the Mann-Kendall and Spearman's rho tests for detecting monotonic trends in hydrological series. J Hydrol. 2002; 259, 254-71.

8. Duhan D, Pandey A. Statistical analysis of long term spatial and temporal trends of precipitation during 1901-2002 at Madhya Pradesh, India. Atmospheric Research. 2013; 122, 136-49.

9. Goyal MK. Statistical Analysis of Long Term Trends of Rainfall During 1901-2002 at Assam, India. Water Resour Manag. 2014; 28, 1501-15.

10. Guhathakurta $P$, Rajeevan M. Trends in the rainfall pattern over India. Int J Climatol. 2008; 28, 1453-69.

11. Hamlin M. The significance of rainfall in the study of hydrological processes at basin scale. J of hydrol. 1983; 65, 73-94.

12. Hirsch RM, Alexander RB, Smith RA. Selection of methods for the detection and estimation of trends in water quality. Water Resour Res. 1991; 27; 803-13.

13. Inclan C, Tiao GC. Use of cumulative sums of squares for retrospective detection of changes of variance. J Am Stat Assoc. 1994; 89, 913-23.

14. Jagannathan P, Parthasarathy B. Trends and periodicities of rainfall over India. Monthly Weather Review. 1973; 101, 371-75.

15. Joshi MK, Pandey A. Trend and spectral analysis of rainfall over India during 1901-2000. Journal of Geophysical Research: Atmospheres. 2011; 116.

16. Kendall M. Rank correlation methods Hafner. New York; 1962.

17. Krishnakumar K, Rao GP, Gopakumar C. Rainfall trends in twentieth century over Kerala, India. Atmospheric Environment. 2009; 43, 1940-44.

18. Kumar V, Jain SK, Singh Y. Analysis of long-term rainfall trends in India. Hydrolog Sci J. 2010; 55:484-96.

19. Kumar V, Singh P, Jain S. Rainfall trends over Himachal Pradesh, Western Himalaya, India. Conference on Development of Hydro Power Projects-A Prospective Challenge; 2005. p. 20-22.
20. Lanzante JR. Resistant, robust and non-parametric techniques for the analysis of climate data: Theory and examples, including applications to historical radiosonde station data. Int J Climatol. 1996; 16, 1197-26.

21. Mann HB. Non-parametrictest against trend. Econometrika. $1945 ; 13: 245-59$.

22. Maragatham RS. Trend analysis of rainfall data-a comparative study of existing methods. International Journal of Physics and Mathematical Sciences.2012; 2(1):13-18.

23. Mooley D, Parthasarathy B. Fluctuations in all-India summer monsoon rainfall during 1871-1978. Climatic Change. 1984; 6, 287-301.

24. Pal I, Al-Tabbaa A. Trends in seasonal precipitation extremes-An indicator of 'climate change'in Kerala, India. J of Hydrol. 2009; 367, 62-9.

25. Patra JP, Mishra A, Singh R, Raghuwanshi N. Detecting rainfall trends in twentieth century (1871-2006) over Orissa State, India. Climatic Change. 2012; 111, 801-17.

26. Rajeevan M, Bhate J, Jaswal A. Analysis of variability and trends of extreme rainfall events over India using 104 years of gridded daily rainfall data. Geophys Res Lett. 2008; 35 .

27. Salas JD. Analysis and modeling of hydrologic time series. Handbook of Hydrology. 1993; 19, 1-72.

28. Sarangi A, Cox C, Madramootoo C. Geostatistical methods for prediction of spatial variability of rainfall in a mountainous region. Transactions of the ASAE. 2005; 48, 943-54.

29. Sati S, Sundriyal Y, Rana N, Dangwal S. Recent landslides in Uttarakhand: nature's fury or human folly. Current Science(Bangalore). 2011; 100, 1617-20.

30. Sen PK. Estimates of the regression coefficient based on Kendall's tau. J Am Stat Assoc. 1968; 63, 1379-89.

31. Shadmani M, Marofi S, Roknian, M. Trend analysis in reference evapotranspiration using Mann-Kendall and Spearman's Rho tests in arid regions of Iran. Water Resour Manag. 2012; 26, 211-24.

32. Siegel S, Castellan N. Nonparametric statistics for the behavioral sciences. McGraw-Hill, New York; 1988.

33. Thapliyal V, Kulshrestha S. Climate changes and trends over India. Mausam. 1991; 42, 333-38.

34. Thiel H. A rank-invariant method of linear and polynomial regression analysis, Part 3. In Proceedings of Koninalijke Nederlandse Akademie van Weinenschatpen A; 1950. p. 1397-12.

35. Worsley KJ. On the likelihood ratio test for a shift in location of normal populations. Journal of the American Statistical Association. 1979; 74:365-67.

36. Xu Z, Li J, Liu C. Long-term trend analysis for major climate variables in the Yellow River basin*. Hydrological Processes. 2007; 21:1935-48. 